\title{
Current trends in bilateral internal thoracic artery use for coronary revascularization: Extending benefit to high-risk patients
}

\author{
Nishant Saran, MBBS, ${ }^{\mathrm{a}}$ Chaim Locker, MD, ${ }^{\mathrm{a}}$ Sameh M. Said, MD, ${ }^{\mathrm{a}}$ Richard C. Daly, MD, ${ }^{\mathrm{a}}$ \\ Simon Maltais, MD, ${ }^{\mathrm{a}}$ John M. Stulak, MD, ${ }^{\mathrm{a}}$ Kevin L. Greason, MD, ${ }^{\mathrm{a}}$ Alberto Pochettino, MD, ${ }^{\mathrm{a}}$ \\ Hartzell V. Schaff, MD, ${ }^{a}$ Joseph A. Dearani, MD, ${ }^{a}$ Lyle D. Joyce, MD, ${ }^{b}$ Brian D. Lahr, MS, ${ }^{c}$ and \\ David L. Joyce, MD
}

\section{ABSTRACT}

Background: We sought to identify the trends in bilateral internal thoracic artery use and determine the degree to which the survival advantage of bilateral internal thoracic artery revascularization persists among perceived "high-risk" patients, compared with the use of left internal thoracic artery alone.

Methods: A retrospective review was conducted of patients who underwent isolated coronary artery bypass grafting for multivessel coronary artery disease at the Mayo Clinic between January 2000 and December 2015. Propensity score matching was performed between patients with bilateral internal thoracic artery and left internal thoracic artery alone grafts (1011 matched pairs). Effect of bilateral internal thoracic artery use on survival in "high-risk" patients (ejection fraction $<40 \%$, body mass index $\geq 30$, age $\geq 70$ years, diabetes, chronic lung disease, cerebrovascular accident) was evaluated.

Results: A total of 6468 isolated coronary artery bypass grafts were performed (5431 using left internal thoracic artery alone, 1037 using bilateral internal thoracic artery). There was an increasing trend in bilateral internal thoracic artery use $(P$ value for linear trend $=.005)$, with the percentage of coronary artery bypass grafting cases with bilateral internal thoracic artery doubling over the last 4 years (13\% in 2012 to $27 \%$ in 2015). Propensity-matched comparisons showed a survival advantage for bilateral internal thoracic artery (hazard ratio, $0.81 ; 95 \%$ confidence interval, $0.66-0.99 ; P=.043)$. Risk of deep sternal wound infection, although higher in the bilateral internal thoracic artery group, was not significant $(1.2 \%$ vs $0.5 \% ; P=.088)$. None of the "high-risk" subsets of patients showed an adverse effect of bilateral internal thoracic artery on survival.

Conclusions: Bilateral internal thoracic artery use in coronary artery bypass grafting is increasing over time. There is a consistent survival benefit with bilateral internal thoracic artery use, extending to patients with higher-risk comorbidities, suggesting the need for further expansion in use of this technique. (J Thorac Cardiovasc Surg 2018;155:2331-43)

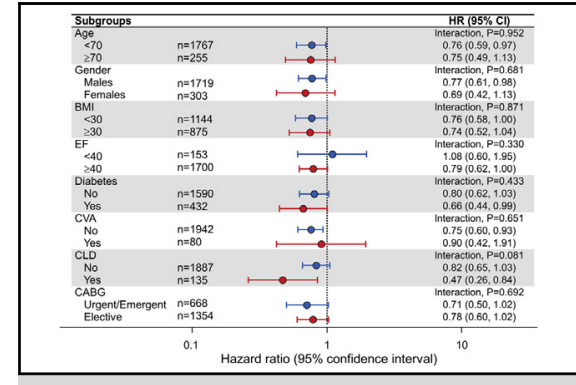

BITA use in perceived high-risk patients.

Central Message

BITA use has a survival advantage over the use of LITA alone, and this benefit extends to the perceived high-risk groups.

Perspective

Perceived high-risk factors, such as low EF obesity, CLD, advancing age, and diabetes, have prevented surgeons to adopt BITA use extensively. We used a propensity score model to compare BITA and LITA-alone use to identify if BITA use offers a survival advantage or not, especially in perceived high-risk patients.

See Editorial Commentary page 2344.
From the ${ }^{\mathrm{a} D e p a r t m e n t}$ of Cardiovascular Surgery, and ${ }^{\mathrm{c}}$ Division of Biomedical Statistics and Informatics, Mayo Clinic, Rochester, Minn; and ${ }^{\mathrm{b}}$ Division of Cardiothoracic Surgery, Medical College of Wisconsin, Milwaukee, Wis.

Read at the 43rd Annual Meeting of The Western Thoracic Surgical Association, Colorado Springs, Colorado, June 21-24, 2017.

Received for publication June 21, 2017; revisions received Nov 19, 2017; accepted for publication Jan 11, 2018; available ahead of print March 15, 2018.

Address for reprints: Nishant Saran, MBBS, Department of Cardiovascular Surgery, Mayo Clinic, 200 First St SW, Rochester, MN 55905 (E-mail: nishu.saran@gmail. com).

$0022-5223 / \$ 36.00$

Copyright (C) 2018 by The American Association for Thoracic Surgery

https://doi.org/10.1016/j.jtcvs.2018.01.094
Coronary artery disease (CAD) accounts for approximately 1 of every 7 deaths in the United States, with approximately 660,000 Americans experiencing a coronary event every

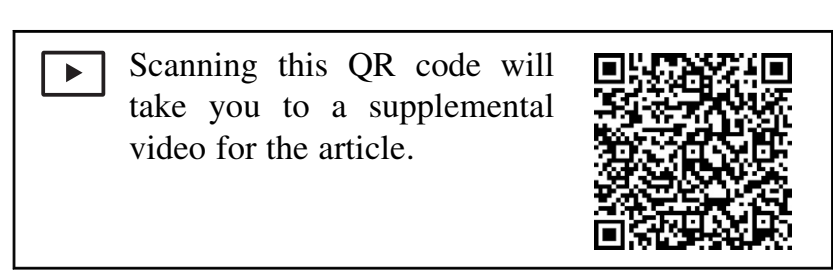




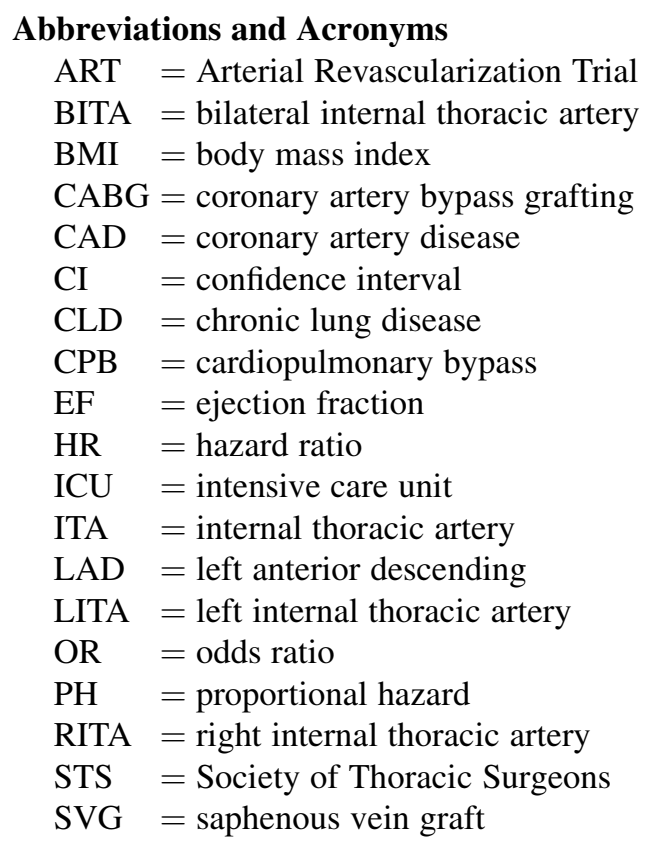

year. ${ }^{1}$ Coronary artery bypass grafting $(\mathrm{CABG})$ has been established as an optimal treatment strategy for patients with multivessel CAD disease. ${ }^{2}$ The traditional revascularization strategy for a multivessel CABG involves placing a left internal thoracic artery (LITA) graft to the left anterior descending (LAD) artery with the use of reverse saphenous vein graft (SVG) to bypass any other diseased vessels. The use of LITA to LAD in CABG has been shown to offer a survival benefit to patients when compared with $\mathrm{SVG}^{3}$ The angiographic patency rates of internal thoracic artery (ITA) at 10 years are higher $(\approx 90 \%-95 \%)$ compared with vein grafts $(\approx 50 \%-75 \%) .{ }^{3-5}$ Over the past decade, several observational studies have shown that the use of a bilateral internal thoracic artery (BITA) revascularization strategy offers a survival advantage over the use of LITA alone for multivessel CAD. ${ }^{6,7}$ However, despite the growing evidence in support of this technique, only $4 \%$ to $12 \%$ of all CABG operations worldwide use a BITA approach. ${ }^{8-10}$ This opposition to BITA grafting is largely based on the perception of increased perioperative risk, in particular the risk of sternal wound infection and myocardial and respiratory morbidity. The perceived "high-risk" factors described in the literature include older age, female sex, diabetes mellitus, obesity, chronic lung disease (CLD), and reduced ejection fraction (EF). ${ }^{11-17}$ The recently published midterm $(<5$ years $)$ results of the Arterial Revascularization Trial (ART) showing no survival benefit with BITA has brought back into contention the need for an additional ITA in CABG. ${ }^{18}$ We sought to identify in our practice trends in BITA use over time and to evaluate the impact of patients' comorbidities on the relative benefit of BITA compared with the use of LITA alone.

\section{MATERIALS AND METHODS}

A total of 9084 patients underwent CABG between January 2000 and December 2015 at our institute. Of these, 6468 patients had isolated CABG for multivessel CAD. A retrospective review of all isolated CABG for multivessel CAD was done after obtaining the necessary approval from the Institutional Review Board, Mayo Clinic. The requirement for individual patient consent was waived because of the study designation as a minimal-risk retrospective study.

All patients who received 2 or more bypass grafts were included in the study. Patients with single bypass graft or any concomitant cardiac surgery were excluded. Patients were divided into 2 groups. The BITA group $(\mathrm{n}=1037)$ included all patients in whom BITA grafts were used, with or without the use of SVG $(55.8 \%)$ or radial artery $(12.8 \%)$. The LITA-alone group $(\mathrm{n}=5431)$ included all patients in whom LITA alone was used with no use of the right internal thoracic artery (RITA). In this group, SVG $(96.3 \%)$ and radial artery $(7.7 \%)$ accounted for the additional bypass grafts. Both skeletonized and pedicled techniques were used for ITA harvesting. Within the BITA group, surgical strategy for grafting included 4 patterns: (1) in situ LITA to LAD with free RITA anastomosed in a T-composite configuration off the side of the LITA to the circumflex and right coronary territories as sequential grafts; (2) in situ LITA to LAD, in situ RITA to circumflex territory via transverse sinus, with or without SVG or radial artery to right coronary territory; (3) in situ RITA to LAD with in situ LITA to circumflex territory, with or without SVG or radial artery graft to right coronary territory; and (4) in situ LITA to LAD, in situ RITA to right coronary territory, with or without SVG or radial artery to circumflex territory. The grafting strategy in the LITA-alone group was always LITA to LAD, with SVG or radial artery graft to the circumflex and right coronary territory. Most of the cases were performed with the use of cardiopulmonary bypass (CPB), whereas few were performed with the off-pump technique (4.7\% and 5.8\% in the BITA and LITA-alone groups, respectively).

Patient data were analyzed according to the Society of Thoracic Surgeons (STS) National Cardiac Surgery Database guidelines and definitions. ${ }^{19}$ The primary outcome of interest was long-term survival after surgery in the 2 study groups defined by BITA or LITA-alone use during CABG. To minimize treatment selection bias, propensity score matching of BITA and LITA-alone patients was performed to produce statistically comparable groups with respect to baseline characteristics: age, gender, smoking status, diabetes, body mass index (BMI), peripheral vascular disease, cerebrovascular accident, CLD, renal failure, EF, left main coronary disease greater than $50 \%$, number of diseased coronary vessels, and nonelective surgery. A total of 1011 matched pairs were ultimately identified. Secondary outcomes included operative characteristics, including CPB and crossclamp times, given the potential for these variables to influence conduit selection, as well as postoperative complications. Analysis of both primary and secondary outcomes emphasized the comparison of matched groups, which were supplemented with risk-adjusted modeling to determine independent effects of BITA use. The perceived "high-risk" preoperative factors were defined as EF less than $40 \%$, BMI $30 \mathrm{~kg} / \mathrm{m}^{2}$ or more, age 70 years or more, diabetes, CLD, and cerebrovascular accident. BITA use in patients with "high-risk" factors was evaluated for a differential effect on survival.

\section{Statistical Methods}

Baseline characteristics are shown as number (percent) for categoric variables, median (interquartile range, range) for continuous variables, or mean (interquartile range, range) for ordinal variables. Baseline differences between BITA and LITA-alone surgery groups were determined using Pearson chi-square tests for categoric variables, Wilcoxon rank-sum tests for 
continuous variables, and Cochran-Armitage proportion trend tests for ordinal variables. Because any 1 of these factors could have influenced the decision to perform the surgery with BITA versus LITA-alone, differences in outcomes between the 2 surgery strategies are susceptible to treatment selection bias. To compensate for the potential confounding from nonrandom treatment selection, propensity score analysis was undertaken in the form of case-matching to produce comparable BITA and LITA-alone groups at the time of surgery. As the basis of matching, the propensity score is a probabilistic prediction of whether the patient underwent BITA and was derived using multivariable logistic regression. All available baseline covariates were included in this propensity model, with continuous covariates modeled flexibly with restricted cubic splines to permit nonlinear effects and any missing data imputed before the analysis. Specifically, we used single imputation based on the Markov chain Monte Carlo method to predict missing values of a target variable using all available data on other baseline covariates. The similarity of baseline characteristics between groups after propensity score matching was assessed to support the validity for comparing the 2 surgery strategies. To this end, absolute standardized differences are reported to express the group comparability both before and after matching.

Comparison of clinical and patient outcomes between propensitymatched groups was achieved by the statistical tests indicated earlier (chi-square test, Wilcoxon rank-sum test) or by survival analysis based on the Kaplan-Meier method with the log-rank test. To assess differences in operative time and intensive care unit (ICU) length of stay or readmission, subset analysis was performed on calendar years 2002 to 2015 because these data were not collected in the STS before then. To assess the independent association of BITA with outcomes after adjustment for relevant baseline covariates, logistic regression models were fitted for binary outcomes and Cox proportional hazards $(\mathrm{PH})$ regression models were fitted for survival outcomes. In the risk-adjusted model for survival time, we included all baseline variables used in the propensity score, in addition to the score itself, to determine whether our finding was robust to comprehensive adjustment. Evidence of heterogeneity in our study results for prespecified, clinically relevant subgroups was investigated by adding a BITA-by-subgroup interaction term to the outcome model and testing whether the treatment effect differed in these high-risk subsets of patients compared with all others. We further examined the sensitivity of our case-matched analysis to selection bias by refitting the survival models on the comprehensive series of patients with the propensity score used as a covariate to adjust for treatment selection. All analyses were performed using SAS software version 9.4 (SAS Institute Inc, Cary, NC).

\section{RESULTS}

Among isolated CABG surgeries performed over the 16-year period, the percentage of CABGs with BITA use showed a significantly increasing temporal trend $(P$ value for linear trend $=0.005$ ) (Figure 1). Although the percentage of CABGs with BITA remained relatively constant from 2000 to 2012 (range from $12 \%$ to $18 \%$ of CABG cases per year), the percentage of CABGs with BITA nearly doubled in the last 4 years (2012-2015, 13\%-27\%, respectively).

Baseline characteristics of the comprehensive and casematched series of BITA and LITA-alone patients are shown in Tables 1 and 2, respectively. Distribution of propensity score by group in comprehensive and case-matched series of patients is shown in Figure 2. Significant differences were found between the original LITA-alone and BITA groups before matching. Patients receiving LITA-alone were older, more often female, and more likely to have diabetes, peripheral vascular disease, hypertension, reduced $\mathrm{EF}$, renal failure, and nonelective CABG.

The BITA group had significantly lower use of additional SVGs $(56.0 \%$ vs $92.3 \% ; P<.001)$ and radial arteries $(12.5 \%$ vs $16.4 \% ; P<.001)$. Compared with the LITAalone group, crossclamp time was longer in the BITA group $(P=.012)$, whereas CPB time was shorter $(P=.011)$. The mean number of grafts used was 3.3 in the BITA group compared with 3.1 in the LITA-alone group $(P<.001)$ and ranged from 2 to 6 grafts in both groups. In analysis restricted to the time frame with available data $(82 \%)$, comparison of treatments in 2002 to 2015 suggested a longer operative time in patients who underwent BITA versus LITA alone (Table 3).

The percentage of patients who underwent prolonged ventilation after surgery was similar between the 2 groups. There was also no significant difference in the duration of

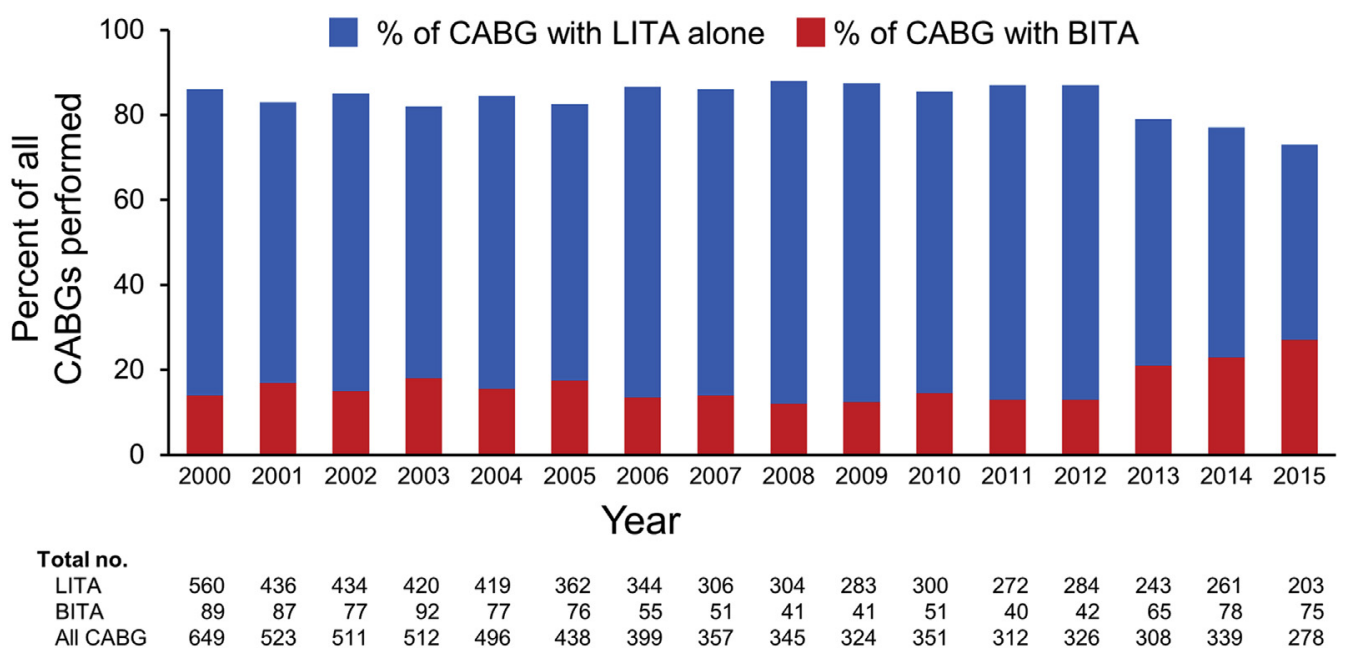

FIGURE 1. Trends in use of BITA and LITA (alone) in isolated CABG performed from 2000 to 2015. CABG, Coronary artery bypass grafting; LITA, left internal thoracic artery; BITA, bilateral internal thoracic artery. 
TABLE 1. Baseline characteristics in original sample

\begin{tabular}{|c|c|c|c|c|c|}
\hline Variable & $\mathbf{N}$ & LITA alone $(n=5431)$ & BITA $(n=1037)$ & $P$ value & $\begin{array}{c}\text { Standardized } \\
\text { difference }\end{array}$ \\
\hline Age at surgery* & 6468 & $70.4(63.3,76.7)[28.9,96.9]$ & $59.2(53.3,65.6)[24.6,86.2]$ & $<.001$ & 1.063 \\
\hline Female & 6468 & $1271(23.4 \%)$ & $150(14.5 \%)$ & $<.001$ & 0.230 \\
\hline Current smoker & 6455 & $686(12.7 \%)$ & $226(21.9 \%)$ & $<.001$ & 0.245 \\
\hline Diabetes & 6468 & $2075(38.2 \%)$ & $217(20.9 \%)$ & $<.001$ & 0.386 \\
\hline $\mathrm{BMI}^{*}$ & 6464 & $29.4(26.3,33.3)[17.0,69.4]$ & $29.1(26.4,32.6)[15.1,58.3]$ & .033 & 0.114 \\
\hline Congestive heart failure & 6468 & $679(12.5 \%)$ & $33(3.2 \%)$ & $<.001$ & 0.352 \\
\hline Peripheral vascular disease & 6467 & $889(16.4 \%)$ & $107(10.3 \%)$ & $<.001$ & 0.179 \\
\hline Cerebrovascular accident & 6461 & $377(6.9 \%)$ & $40(3.9 \%)$ & $<.001$ & 0.137 \\
\hline Cerebrovascular disease & 6468 & $936(17.2 \%)$ & $85(8.2 \%)$ & $<.001$ & 0.274 \\
\hline CLD & 6465 & $638(11.8 \%)$ & $70(6.8 \%)$ & $<.001$ & 0.173 \\
\hline Hypertension & 6468 & $4571(84.2 \%)$ & $771(74.3 \%)$ & $<.001$ & 0.244 \\
\hline Dyslipidemia & 6467 & $4975(91.6 \%)$ & $983(94.8 \%)$ & $<.001$ & 0.126 \\
\hline $\mathrm{EF}^{*}$ & 6005 & $56(45,63)[13,89]$ & $59(51,64)[13,87]$ & $<.001$ & 0.275 \\
\hline Left main coronary disease $(\geq 50 \%)$ & 6359 & $2038(38.1 \%)$ & $352(35.0 \%)$ & .060 & 0.065 \\
\hline Recent atrial fibrillation/flutter & 6363 & $321(6.0 \%)$ & $29(2.8 \%)$ & $<.001$ & 0.156 \\
\hline NYHA classification $\dagger$ & 6237 & $3.0(2,4)[1,4]$ & $2.8(2,4)[1,4]$ & $<.001 \dagger$ & 0.226 \\
\hline Renal failure & 6467 & $320(5.9 \%)$ & $20(1.9 \%)$ & $<.001$ & 0.206 \\
\hline Dialysis & 6468 & $85(1.6 \%)$ & $5(0.5 \%)$ & .006 & 0.108 \\
\hline Year of surgery* & 6468 & $2006(2002,2010)[2000,2015]$ & $2006(2003,2012)[2000,2015]$ & .005 & 0.105 \\
\hline Any prior cardiac operations & 6468 & $108(2.0 \%)$ & $12(1.2 \%)$ & .069 & 0.067 \\
\hline Previous CABG & 6468 & $88(1.6 \%)$ & $9(0.9 \%)$ & .068 & 0.068 \\
\hline Previous valve surgery & 6468 & $15(0.3 \%)$ & $1(0.1 \%)$ & .286 & 0.042 \\
\hline Creatinine level* & 6461 & $1.1(1.0,1.3)[0.3,14.2]$ & $1.1(0.9,1.2)[0.6,12.3]$ & $<.001$ & 0.179 \\
\hline $\begin{array}{l}\text { No. of diseased vessels } \\
2 \\
3\end{array}$ & 6468 & $\begin{array}{l}1015(18.7 \%) \\
4416(81.3 \%)\end{array}$ & $\begin{array}{l}233(22.5 \%) \\
804(77.5 \%)\end{array}$ & .005 & 0.094 \\
\hline Mitral stenosis & 6467 & $38(0.7 \%)$ & $0(0.0 \%)$ & .007 & 0.119 \\
\hline Tricuspid regurgitation $\dagger$ & 6468 & $0.8(0.0,1.0)[0,4]$ & $0.6(0.0,1.0)[0,3]$ & $<.001 \dagger$ & 0.259 \\
\hline Surgery status & 6468 & & & $<.001$ & \\
\hline Elective & & $3192(58.8 \%)$ & $705(68.0 \%)$ & & 0.192 \\
\hline Urgent & & $2103(38.7 \%)$ & $325(31.3 \%)$ & & 0.155 \\
\hline Emergency & & $136(2.5 \%)$ & $7(0.7 \%)$ & & 0.147 \\
\hline
\end{tabular}

$\mathrm{N}$ is the total number of nonmissing responses for each variable (proportion of subjects missing data ranged from $0 \%$ to $7 \%$ for all baseline variables). Unless stated otherwise, differences between groups were analyzed with Pearson chi-square test for categoric variables and Wilcoxon rank-sum test for continuous variables. Absolute standardized differences are used to express the baseline comparability between groups for each variable before propensity matching. LITA, Left internal thoracic artery; BITA, bilateral internal thoracic artery; $B M I$, body mass index; $C L D$, chronic lung disease; $E F$, ejection fraction; $N Y H A$, New York Heart Association; $C A B G$, coronary artery bypass grafting. *Continuous variables are described by percentile values: median (IQR) [range]. †Ordinal variables presented as mean (IQR) [range] and analyzed by Cochran-Armitage proportion trend test.

hospital stay or in the number of patients readmitted within 30 days of surgery (Table 3 ). However, for the matched subset between 2002 and 2015, patients with BITA had a slightly shorter length of ICU stay (median, 22 vs 23 hours; $P=.003$ ).

The incidence of overall sternal-site infection (superficial or deep) was higher in the BITA group than in the LITA- alone group ( $3.1 \%$ vs $1.4 \% ; P=.010)$, with the odds of infection increased 2-fold with BITA (odds ratio [OR], 2.28; 95\% confidence interval [CI], 1.21-4.32). This higher risk among the BITA group persisted after adjustment for suspected risk factors, including sex, BMI, diabetes, CLD, and year of CABG (OR, 2.39, 95\% CI, 1.25-4.57; $P=.008)$. However, the percentage of patients with deep 
TABLE 2. Baseline characteristics in matched sample

\begin{tabular}{|c|c|c|c|c|c|}
\hline Variable & $\mathbf{N}$ & LITA alone $(n=1011)$ & BITA $(n=1011)$ & $P$ value & $\begin{array}{c}\text { Standardized } \\
\text { difference }\end{array}$ \\
\hline Age at surgery* & 2022 & $59.4(53.7,65.6)[31.8,91.0]$ & $59.6(53.7,65.8)[24.6,86.2]$ & .901 & 0.024 \\
\hline Female & 2022 & $154(15.2 \%)$ & $149(14.7 \%)$ & .755 & 0.014 \\
\hline Current smoker & 2017 & $223(22.1 \%)$ & $221(21.9 \%)$ & .924 & 0.004 \\
\hline Diabetes & 2022 & $215(21.3 \%)$ & $217(21.5 \%)$ & .914 & 0.005 \\
\hline Body mass index* & 2019 & $29.4(26.2,33.0)[18.1,64.7]$ & $29.2(26.5,32.6)[15.1,58.3]$ & .659 & 0.030 \\
\hline Congestive heart failure & 2022 & $36(3.6 \%)$ & $33(3.3 \%)$ & .713 & 0.016 \\
\hline Peripheral vascular disease & 2022 & $98(9.7 \%)$ & $105(10.4 \%)$ & .604 & 0.023 \\
\hline Cerebrovascular accident & 2021 & $41(4.1 \%)$ & $39(3.9 \%)$ & .816 & 0.010 \\
\hline Cerebrovascular disease & 2022 & $83(8.2 \%)$ & $84(8.3 \%)$ & .936 & 0.004 \\
\hline CLD & 2022 & $68(6.7 \%)$ & $67(6.6 \%)$ & .929 & 0.004 \\
\hline Hypertension & 2022 & $777(76.9 \%)$ & $758(75.0 \%)$ & .323 & 0.044 \\
\hline Dyslipidemia & 2022 & $962(95.2 \%)$ & $960(95.0 \%)$ & .837 & 0.009 \\
\hline $\mathrm{EF}^{*}$ & 1853 & $58(51,64)[13,89]$ & $59(50,64)[13,87]$ & .970 & 0.000 \\
\hline Left main coronary disease $(\geq 50 \%)$ & 1970 & $353(35.8 \%)$ & $346(35.2 \%)$ & .793 & 0.012 \\
\hline Recent atrial fibrillation/flutter & 2002 & $30(3.0 \%)$ & $28(2.8 \%)$ & .784 & 0.012 \\
\hline NYHA classification $\dagger$ & 1922 & $2.8(2,4)[1,4]$ & $2.8(2,4)[1,4]$ & $.546 \dagger$ & 0.028 \\
\hline Renal failure & 2021 & $15(1.5 \%)$ & $20(2.0 \%)$ & .396 & 0.038 \\
\hline Dialysis & 2022 & $4(0.4 \%)$ & $5(0.5 \%)$ & .738 & 0.015 \\
\hline Year of surgery* & 2022 & $2006(2002,2011)[2000,2015]$ & $2006(2003,2011)[2000,2015]$ & .433 & 0.034 \\
\hline Any prior cardiac operations & 2022 & $14(1.4 \%)$ & $12(1.2 \%)$ & .693 & 0.018 \\
\hline Previous CABG & 2022 & $11(1.1 \%)$ & $9(0.9 \%)$ & .653 & 0.020 \\
\hline Previous valve surgery & 2022 & $1(0.1 \%)$ & $1(0.1 \%)$ & $>.999$ & 0.000 \\
\hline Creatinine level* & 2018 & $1.1(0.9,1.2)[0.3,9.5]$ & $1.1(0.9,1.2)[0.6,12.3]$ & .796 & 0.013 \\
\hline $\begin{array}{l}\text { No. of diseased vessels } \\
2 \\
3\end{array}$ & 2022 & $\begin{array}{l}251(24.8 \%) \\
760(75.2 \%)\end{array}$ & $\begin{array}{l}225(22.3 \%) \\
786(77.7 \%)\end{array}$ & .173 & 0.061 \\
\hline Mitral stenosis & 2021 & $0(0.0 \%)$ & $0(0.0 \%)$ & & \\
\hline Tricuspid regurgitation $\dagger$ & 2022 & $0.6(0,1)[0,4]$ & $0.6(0,1)[0,3]$ & $.825 \dagger$ & 0.010 \\
\hline $\begin{array}{l}\text { Surgery status } \\
\text { Elective } \\
\text { Urgent }\end{array}$ & 2022 & $\begin{array}{l}670(66.3 \%) \\
334(33.0 \%)\end{array}$ & $\begin{array}{l}684(67.7 \%) \\
320(31.7 \%)\end{array}$ & .801 & $\begin{array}{l}0.029 \\
0.030\end{array}$ \\
\hline Emergency & & $7(0.7 \%)$ & $7(0.7 \%)$ & & 0.000 \\
\hline
\end{tabular}

$\mathrm{N}$ is the total number of nonmissing responses for each variable (proportion of subjects missing data ranged from $0 \%$ to $8 \%$ for all baseline variables). Unless stated otherwise, differences between groups were analyzed with Pearson chi-square test for categoric variables and Wilcoxon rank-sum test for continuous variables. Absolute standardized differences are used to express the baseline comparability between groups for each variable after propensity matching. LITA, Left internal thoracic artery; BITA, bilateral internal thoracic artery; $C L D$, chronic lung disease; $E F$, ejection fraction; $N Y H A$, New York Heart Association; $C A B G$, coronary artery bypass grafting. *Continuous variables are described by percentile values: median (IQR) [range]. †Ordinal variables presented as mean (IQR) [range] and analyzed by Cochran-Armitage proportion trend test.

sternal wound infections was not significantly higher in the BITA group compared with the LITA-alone group $(1.2 \%$ vs $0.5 \% ; P=.088)$.

There was no significant difference in operative mortality between the matched BITA and LITA-alone groups $(0.3 \%$ vs $0.6 \% ; P=.316)$. However, survival over long-term follow-up was significantly improved in the BITA group (1, 5, and 10-year survival estimates: $98.6 \%, 93.8 \%$,
$82.4 \%$, respectively) relative to the LITA-alone group $(98.0 \%, 91.8 \%, 79.5 \%$, respectively; $P=.031)$ (Figure 3). In risk-adjusted models, BITA was associated with a $19 \%$ risk reduction in death after adjustment for propensity alone (hazard ratio [HR], 0.81; 95\% CI, 0.66-0.99) and a $26 \%$ risk reduction after additional adjustment for all baseline covariates used in the propensity model (HR, 0.74; $95 \%$ CI, 0.60-0.92). Sensitivity analysis performed on the 
Original Sample $(n=6468)$

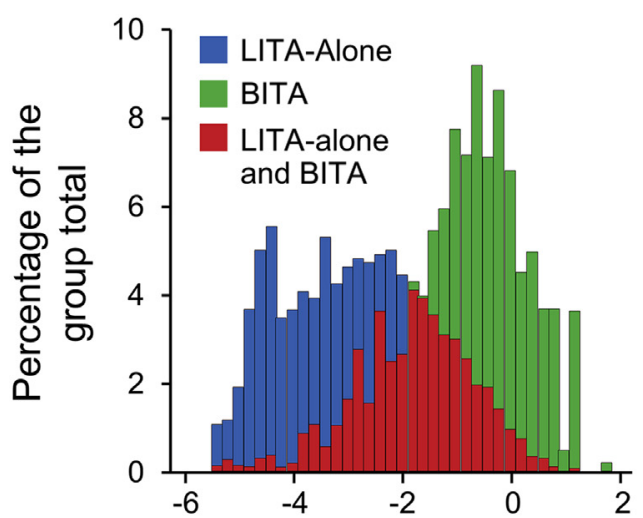

PS-Matched Subset $(n=2022)$

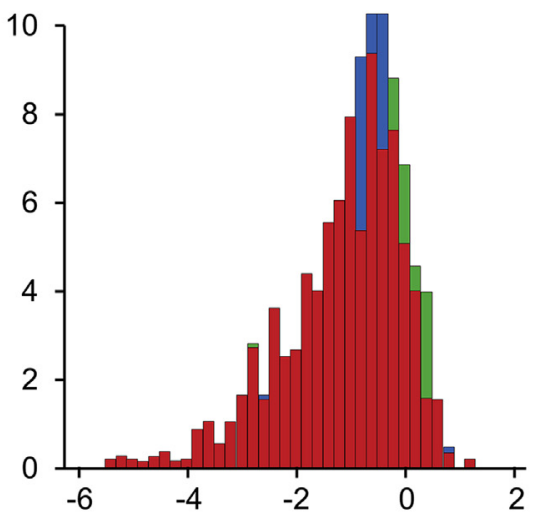

\section{Distribution of propensity score}

FIGURE 2. Distribution of propensity score by group in comprehensive and case-matched series of patients. PS, Propensity score; LITA, left internal thoracic artery; BITA, bilateral internal thoracic artery.

larger cohort with propensity score used as a covariate produced results similar to those from the case-matched analysis, with patients in the BITA group having favorable survival (20\%-22\% risk reduction). Survival analysis on the treatment interaction between BITA versus LITAalone and "high-risk" patient subsets revealed no evidence of heterogeneity in our results. The relative efficacy of BITA versus LITA-alone on survival was not significantly

TABLE 3. Comparison of operative and postoperative measures between matched groups

\begin{tabular}{|c|c|c|c|c|}
\hline Variable & $\mathbf{N}$ & LITA alone $(n=1011)$ & BITA $(n=1011)$ & $P$ value \\
\hline Use of SVG & 2022 & $933(92.3 \%)$ & $566(56.0 \%)$ & $<.001$ \\
\hline Use of radial grafts & 2022 & $166(16.4 \%)$ & $126(12.5 \%)$ & .011 \\
\hline Crossclamp time* & 1968 & $53(40,66)[0,128]$ & $55(41,68)[0,143]$ & .012 \\
\hline Perfusion time* & 1967 & $78(63,98)[0,267]$ & $75(59,97)[0,213]$ & .011 \\
\hline Incision time $(\mathrm{min})^{*}$ & 1667 & $254(221,293)[39,1426]$ & $298(251,341)[121,1134]$ & $<.001$ \\
\hline No. of grafts used $\dagger$ & 2022 & $3.1(3,4)[2,6]$ & $3.3(3,4)[2,6]$ & $<.001 \dagger$ \\
\hline Hospital length of stay, $\mathrm{d}^{*}$ & 2022 & $5(5,6)[0,75]$ & $5(5,6)[0,41]$ & .898 \\
\hline Hospital readmission within $30 \mathrm{~d}$ & 1989 & $79(7.9 \%)$ & $75(7.5 \%)$ & .742 \\
\hline ICU length of stay, $\mathrm{h}^{*}$ & 1667 & $23(20,28)[0,1236]$ & $22(19.5,25)[5,631]$ & .003 \\
\hline ICU readmission within $30 \mathrm{~d}$ & 1667 & $17(2.0 \%)$ & $14(1.7 \%)$ & .575 \\
\hline Complication-prolonged ventilation & 2022 & $44(4.4 \%)$ & $43(4.3 \%)$ & .913 \\
\hline Complication-sternal infection, superficial or deep & 2022 & $14(1.4 \%)$ & $31(3.1 \%)$ & .010 \\
\hline Complication-sternal infection, deep & 2022 & $5(0.5 \%)$ & $12(1.2 \%)$ & .088 \\
\hline Death within $30 \mathrm{~d}$ or during hospitalization & 2022 & $6(0.6 \%)$ & $3(0.3 \%)$ & .316 \\
\hline Survival over follow-up $\ddagger$ & 2022 & & & .031 \\
\hline $1 \mathrm{y}$ & & $98.0 \%(18)$ & $98.6 \%(13)$ & \\
\hline $5 \mathrm{y}$ & & $91.8 \%(65)$ & $93.8 \%(47)$ & \\
\hline $10 \mathrm{y}$ & & $79.5 \%(132)$ & $82.4 \%(107)$ & \\
\hline Total No. of deaths & & 203 & 168 & \\
\hline
\end{tabular}

$\mathrm{N}$ is the total number of nonmissing responses. The proportion of subjects missing data was minimal (range, $0 \%-3 \%$ ), with the exception of incision time and ICU length of stay and readmission (STS data collection for these variables started in 2002, resulting in $18 \%$ of these subjects missing data). Unless stated otherwise, differences between groups were analyzed with Pearson chi-square test for categoric variables and Wilcoxon rank-sum test for continuous variables. LITA, Left internal thoracic artery; BITA, bilateral internal thoracic artery; $S V G$, saphenous vein graft; $I C U$, intensive care unit. *Continuous variables are described by percentile values: median (IQR) [range]. $\dagger$ Ordinal variables presented as mean (IQR) [range] and analyzed by Cochran-Armitage proportion trend test. †़Survival analysis was by the Kaplan-Meier method with the log-rank test; tabulated values are percentages of patients alive (cumulative number of deaths) at each follow-up interval for each group. 


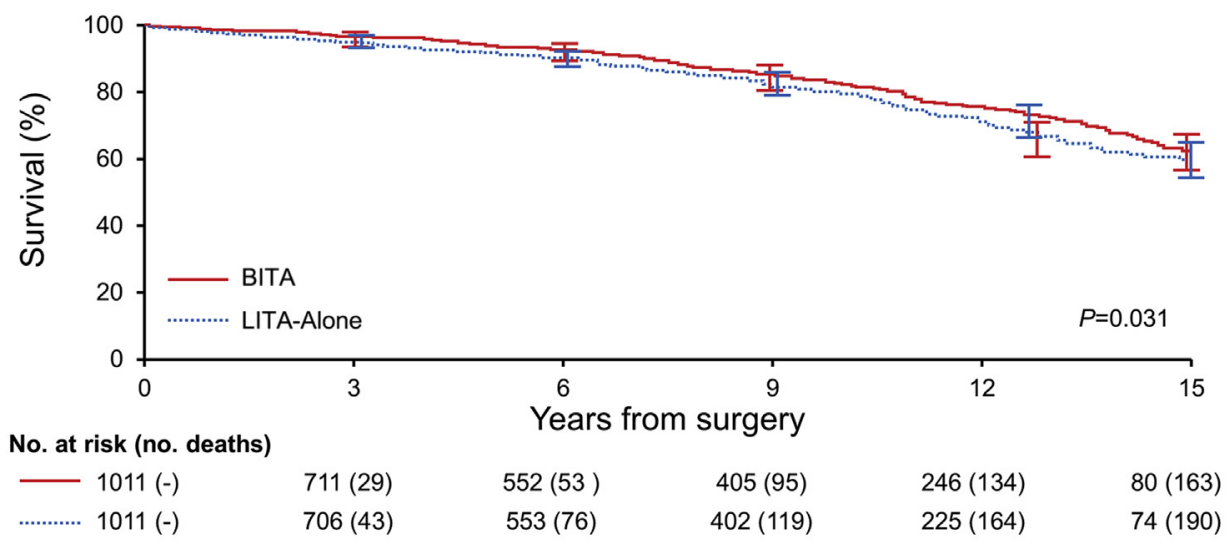

\begin{tabular}{|l|c|c|}
\hline \multirow{2}{*}{ Propensity Score (PS) Method } & \multicolumn{2}{|c|}{ Effect of BITA After PS Adjustment } \\
\cline { 2 - 3 } & Adjusted for PS Alone ${ }^{1}$ & Adjusted for PS + BL Covariates ${ }^{2}$ \\
\hline PS Case-Matching (N=2022) & $0.81(0.66,0.99)[0.043]$ & $0.74(0.60,0.92)[0.006]$ \\
\hline PS as Continuous Covariate $(\mathrm{N}=6460)$ & $0.80(0.68,0.95)[0.009]$ & $0.78(0.66,0.93)[0.005]$ \\
\hline
\end{tabular}

Values are hazard ratios $(95 \% \mathrm{Cl})[\mathrm{p}$-value] estimated in Cox PH regression under both forms of PS analysis

${ }^{1}$ Cox models for both propensity methods included the PS modeled flexibly as a covariate using restricted cubic splines

${ }^{2}$ To control for patient heno

${ }^{2}$ To control for patient heterogeneity the models were additionally adjusted for all baseline covariates used in the propensity score, with any

FIGURE 3. Survival analysis of propensity score-matched groups. BITA, Bilateral internal thoracic artery; LITA, left internal thoracic artery; PS, propensity score; $B L$, baseline; $C I$, confidence interval.

different between high- and low-risk levels defined by age $(P$ value for interaction $=.952), \mathrm{EF}(P=.330)$, BMI $(P=.871)$, gender $(P=.681)$, diabetes $(P=.433)$, cerebrovascular accident $(P=.651), \mathrm{CLD}(P=.081)$, and nonelective surgery $(P=.692)$ (Figure 4$)$.

\section{DISCUSSION}

This study, involving a large cohort of patients with isolated multivessel CAD, shows that the BITA use rate in our institution is increasing, with $27 \%$ of multivessel CABGs performed in 2015 using BITA grafts. Furthermore, the

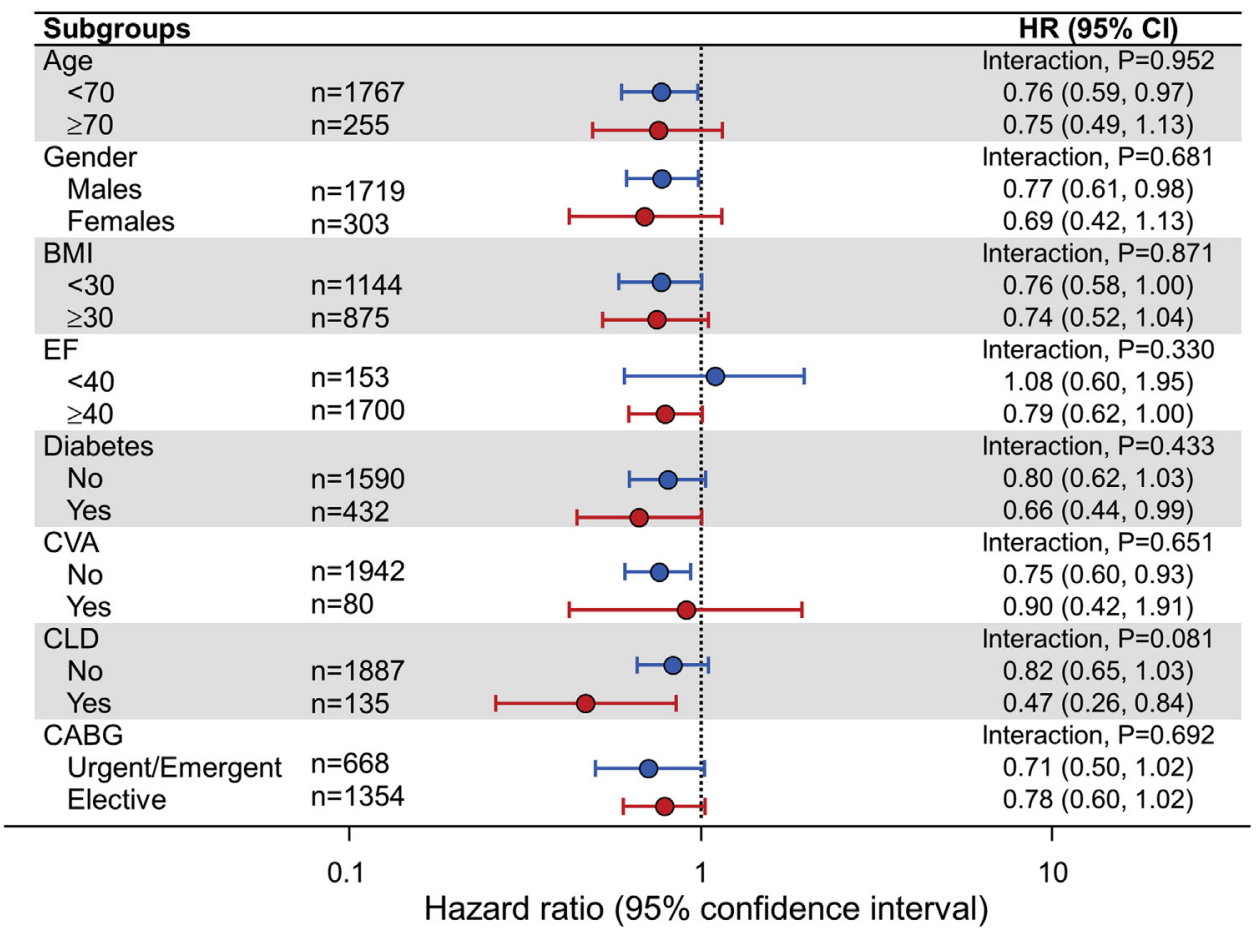

FIGURE 4. Association of BITA with survival time in clinically relevant subgroups. $H R$, Hazard ratio; $C I$, confidence interval; $B M I$, body mass index; $E F$, ejection fraction; $C V A$, cerebrovascular accident; $C L D$, chronic lung disease; $C A B G$, coronary artery bypass grafting. 


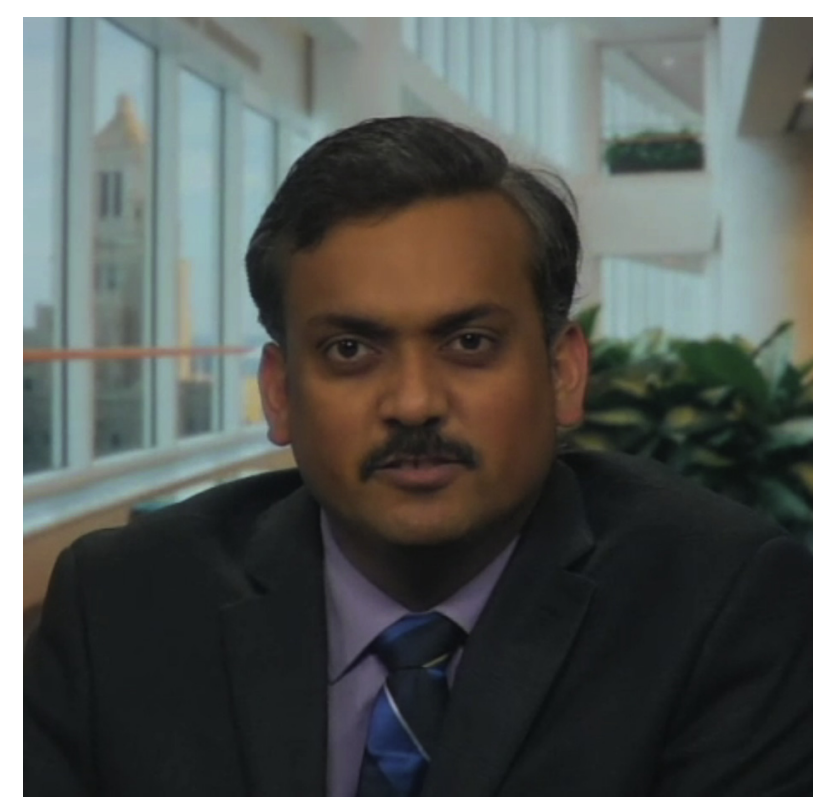

VIDEO 1. Author's take on why the use of BITA should expand. Video available at: http://www.jtcvsonline.org/article/S0022-5223(18)30400-8/ fulltext.

survival advantage of BITA compared with LITA-alone was shown with a $19 \%$ risk reduction in death. None of the "high-risk" subsets of patients showed an adverse effect of BITA on survival (Video 1).

Taggart and colleagues ${ }^{18}$ published the 5 -year results of the randomized trial of BITA versus single ITA grafts. The results showed no significant difference between those receiving single ITA grafts and those receiving BITA grafts with regard to mortality or the rates of cardiovascular events at 5 years of follow-up. However, the BITA group had more sternal wound complications. ${ }^{18}$ This has again raised the debate about the superiority of BITA grafting and the perceived high perioperative risks that has prevented a more liberal use of BITA worldwide. This perception stemmed from previous reports showing BITA use to be associated with the need for prolonged postoperative ventilatory support ${ }^{20}$; increased operative time ${ }^{21}$; higher sternal infection rates, especially in female patients and patients with diabetes, obesity, and $\operatorname{CLD}^{2,11,15,16}$; and lack of survival benefit in elderly patients. ${ }^{13,22}$ This has prevented surgeons worldwide from adopting BITA as a preferred grafting strategy, even in patients who could presumably benefit from it. ${ }^{23}$

The reported BITA use rates are $4 \%$ in the United States, ${ }^{8} 12 \%$ in Europe, ${ }^{9}$ and $12.6 \%$ in Australia. ${ }^{10} \mathrm{~A}$ Swedish study recently published that only $1 \%$ of the patients who underwent CABG between 1997 and 2008 received BITA grafts, ${ }^{24}$ whereas in Canada, a survey found that only $40 \%$ of the surgeons used BITA in $5 \%$ to $25 \%$ of their CABG cases, whereas $37 \%$ used BITA in less than $5 \%$ of their cases. ${ }^{25} \mathrm{~A}$ similar recent survey from India shows that $18 \%$ of surgeons do not use BITA at all, whereas $22 \%$ use BITA in $0 \%$ to $5 \%$ of their cases. ${ }^{26}$ Of the 43,823 patients identified from the Virginia Cardiac Surgery Quality Initiative data registry who underwent CABG, only $3 \%$ received BITA. ${ }^{23}$ In our institution, the total number of CABG cases declined from 649 in 2000 to 312 in 2011, with a corresponding decline in BITA numbers. However, between 2012 and 2015, the number of BITA cases increased 2-fold (13\% to $27 \%)$ despite a continued decline in the number of $\mathrm{CABG}$ cases (Figure 1). The decline in the total number of CABG cases is a reflection of the general trend in coronary revascularization practice. This increasing trend $(P=.005)$ in BITA use is a reflection of a deliberate change in our practice based on our published results in 2012, which showed that multiarterial grafting ( $>85 \%$ with BITA) conferred a significant survival benefit. ${ }^{27}$

In a matched cohort of patients, Grau and colleagues ${ }^{28}$ found that use of BITA over LITA-only had a 10\% survival advantage at 10 years and $18 \%$ at 15 years follow-up. A recent meta-analysis from 20 observational studies enrolling more than 70,000 patients reported that BITA grafting significantly reduced long-term mortality with a pooled HR of $0.80 .^{7}$ This correlates with our findings of reduced long-term mortality in the BITA group with an HR of 0.81 and 0.80 from case-matched and covariateadjusted propensity score analyses. The survival benefit of BITA extends over longer follow-up and the curves appear to diverge more with time. Of note, in our previous report on a matched cohort of patients undergoing CABG between 1993 and 2009, the 5- and 10-year survivals of patients receiving multiarterial grafts versus those receiving LITA/ SVG grafts were similar to patients treated with BITA versus LITA-alone in the current study, with the gap further increasing at 15 years of follow-up. ${ }^{27}$

The lack of survival benefit with BITA in the ART at 5 years may be related to asymptomatic vein-graft failure, improved medical therapy, possible differences in surgical techniques at different centers involved in this multicenter trial, and some methodological shortcomings. ${ }^{18,29}$ Because the survival curves of patients operated on with vein grafts show a steeper decline after 7 years, ${ }^{5}$ and the survival benefit of BITA tends to increase over time, the longterm results of the ART would better reflect on BITA use.

In our study, the relative efficacy of BITA versus LITAalone was not significantly different in specific "highrisk" subsets when compared with patients who were not high risk. Some recent studies, reporting BITA use rates of greater than $30 \%$, have demonstrated a clear survival benefit of BITA in patients aged more than 70 years, ${ }^{30}$ whereas other studies have advocated for an age cutoff at 60 years ${ }^{13}$ or 69 years ${ }^{22}$ under the premise that BITA loses its survival benefit in elderly patients. We found no adverse effect of age 70 years or more on the survival benefit 
conferred by BITA over LITA-alone. Low use rates of BITA in some of these studies show a somewhat selective approach in patient selection, and thereby the differences in survival may not be as apparent. ${ }^{30}$

Many surgeons are averse to using BITA as harvesting of an additional ITA increases the operative time. Taggart and colleagues $^{21}$ found that there is approximately half an hour increase in operative time. This is similar to our practice wherein the median operative time increased by 44 minutes. Although the operative and crossclamp times increased with BITA, there was a reduction in CPB time, probably related to a lower number of proximal anastomoses performed in BITA cases with the composite-T sequential and in situ grafting techniques. We also did not find any increase in the length of hospital stay. BITA cases had a slightly shorter ICU stay. The increase in operative time should not be a deterrent in using BITA given the survival advantage observed in our study and others.

Some studies have raised concerns about the need for prolonged postoperative ventilatory support ${ }^{20}$ in BITA cases with CLD. However, later studies have shown that any concern for increased respiratory complications after BITA is unfounded. ${ }^{14}$ Our study found no significant difference in the need for prolonged postoperative ventilatory support between BITA and LITA-alone groups, besides the absence of any adverse effect of CLD on the survival benefit of BITA.

Diabetes and reduced EF are known risk factors for reduced survival. ${ }^{31}$ Endo and colleagues ${ }^{31}$ demonstrated that survival benefit may be limited in patients with diabetes and EF $40 \%$ or less because of an unavoidable high cardiac death rate. A recent study ${ }^{32}$ has shown an improved survival in diabetic patients with BITA grafts versus LITA-alone, with an HR of 0.73. Our study also found that reduced EF and diabetes have no adverse effect on the survival benefit conferred by BITA. Given the smaller size of coronary vessels and more severe coronary disease, diabetic patients are more likely to benefit from BITA grafting.

The increased incidence of sternal infections in patients with diabetes, especially obese diabetic women ${ }^{15}$ and CLD,${ }^{16}$ has somewhat prevented surgeons from adopting BITA grafting. The incidence of overall sternal-site infection in the BITA group in this study was approximately 2-fold higher (OR, 2.28) than matched patients in the LITA-alone group $(3.1 \%$ vs $1.4 \% ; P=.010)$. This higher risk among BITA cases persisted after adjustment for sex, BMI, diabetes, CLD, and year of CABG (OR, 2.39). Of note, there was no significant difference in the rates of deep-sternal infections between the 2 groups. The low number of deep-sternal infections in our study, although desirable, limited our statistical analysis. It has been shown that the use of skeletonized BITA reduces the incidence of sternal-site infections, particularly in patients with diabetes. ${ }^{33}$ Findings from the ART showed that using a skeletonized technique for harvesting BITA resulted in similar rates of sternal wound complications compared with harvesting a single ITA with the standard pedicled technique. ${ }^{34}$ In our current practice, we aim to harvest the ITAs with an almost exclusive use of skeletonized technique.

\section{Study Limitations}

The study is limited by inherent disadvantages of a retrospective single-center design. In addition, even after controlling for all known variables in the propensity score model, we cannot exclude treatment selection bias based on nonmeasurable variables (eg, patient fitness, surgeon bias). Although most of our variables had little to no missing data, operative time and ICU stay were added to the STS data collection in 2002. We recognize this restricts those particular inferences to the years 2002 to 2015, although the missing subset is small $(18 \%)$ and would likely not have negated these findings. Use of multiple grafting strategies and the likely unaccounted variability of target lesions might have biased our results. Nevertheless, our results show that despite the multiplicity of revascularization strategy, a second ITA offers a distinct survival advantage and remains the superior bypass graft. Finally, we have used an end point of all-cause mortality as the basis of treatment comparison because of the lack of information in our database regarding long-term follow-up of major adverse cardiac events or cause of death. This may limit the applicability of our findings even though all-cause mortality has been shown to be a better end point compared with cause-specific mortality in coronary interventions. ${ }^{35}$

\section{CONCLUSIONS}

The study shows an increasing utilization rate of BITA in Mayo Clinic, Rochester. Expansion of the patient population selected for BITA revascularization seems to be supported by the favorable outcomes achieved even within the "high-risk" patient categories. Although the optimal use of BITA remains to be clearly defined, our data support more extensive use of BITA in patients with multivessel CAD.

\section{Conflict of Interest Statement}

Authors have nothing to disclose with regard to commercial support.

\section{References}

1. Mozaffarian D, Benjamin EJ, Go AS, Arnett DK, Blaha MJ, Cushman M, et al. Heart disease and stroke statistics-2016 update: a report from the American Heart Association. Circulation. 2016;133:38-60.

2. Taggart DP. CABG is still the best treatment for multivessel and left main disease, but patients need to know. Ann Thorac Surg. 2006;82:1966-75.

3. Loop FD, Lytle BW, Cosgrove DM, Stewart RW, Goormastic M, Williams GW, et al. Influence of the internal-mammary-artery graft on 10-year survival and other cardiac events. N Engl J Med. 1986;314:1-6. 
4. Cameron A, Davis KB, Green G, Schaff HV. Coronary bypass surgery with internal-thoracic-artery grafts-effects on survival over a 15 -year period. $N$ Engl J Med. 1996;334:216-9.

5. Fitzgibbon GM, Kafka HP, Leach AJ, Keon WJ, Hooper D, Burton JR, et al. Coronary bypass graft fate and patient outcome: angiographic follow-up of 5,065 grafts related to survival and reoperation in 1,388 patients during 25 years. $J$ Am Coll Cardiol. 1996;28:616-26.

6. Taggart DP, D'Amico R, Altman DG. Effect of arterial revascularization on survival: a systematic review of studies comparing bilateral and single internal mammary arteries. Lancet. 2001;358:870-5.

7. Takagi H, Goto SN, Watanabe T, Mizuno Y, Kawai N, Umemoto T. A metaanalysis of adjusted hazard ratios from 20 observational studies of bilateral versus single internal thoracic artery coronary artery bypass grafting. $J$ Thorac Cardiovasc Surg. 2014;148:1282-90.

8. El-Bardissi AW, Aranki SF, Sheng S, O’Brien SM, Greenberg CC, Gammie JS, et al. Trends in isolated coronary artery bypass grafting: an analysis of the Society of Thoracic Surgeons adult cardiac surgery database. J Thorac Cardiovasc Surg. 2012;143:273-81.

9. Kappetein AP, Dawkins KD, Mohr FW, Morice FC, Mack MJ, Russell ME, et al. Current percutaneous coronary intervention and coronary artery bypass grafting practices for three-vessel and left main coronary artery disease. Insights from the SYNTAX run-in phase. Eur J Cardiothorac Surg. 2006;29:486-91.

10. Yan BP, Clark DJ, Buxton B, Ajani AE, Smith JA, Duffy SJ, et al; on behalf of the Australasian Society of Cardiac and Thoracic Surgeons (ASCTS), the Melbourne Interventional Group (MIG). Clinical characteristics and early mortality of patients undergoing coronary artery bypass grafting compared to percutaneous coronary intervention: insights from the Australasian Society of Cardiac and Thoracic Surgeons (ASCTS) and the Melbourne interventional group (MIG) registries. Heart Lung Circ. 2009;18:184-90.

11. Kouchoukos NT, Wareing TH, Murphy SF, Pelate C, Marshall WG Jr. Risks of bilateral internal mammary artery bypass grafting. Ann Thorac Surg. 1990;49: 210-7.

12. Vallely MP, Edelman JJB, Wilson MK. Bilateral internal mammary arteries: evidence and technical consideration. Ann Cardiothorac Surg. 2013:2:570-7.

13. Mohammadi S, Dagenais F, Doyle D, Mathieu P, Baillot R, Charbonneau E, et al. Age cut-off for the loss of benefit from bilateral internal thoracic artery grafting. Eur J Cardiothorac Surg. 2008;33:977-82.

14. Taggart DP. Respiratory dysfunction after cardiac surgery: effects of avoiding cardiopulmonary bypass and the use of bilateral internal mammary arteries. Eur J Cardiothorac Surg. 2000;18:31-7.

15. Matsa M, Paz Y, Gurevitch J, Shapira I, Kramer A, Pevny D, et al. Bilateral skeletonized internal thoracic artery grafts in patients with diabetes mellitus. $J$ Thorac Cardiovasc Surg. 2001;121:668-74.

16. Sofer D, Gurevitch J, Shapira I, Paz Y, Matsa M, Kramer A, et al. Sternal wound infections in patients after coronary artery bypass grafting using bilateral skeletonized internal mammary arteries. Ann Surg. 1999;229:585-90.

17. Kurlansky PA, Traad EA, Dorman MJ, Galbut DL, Zucker M, Ebra G, et al. Efficacy of single versus bilateral internal mammary artery grafting in women: a long-term study. Ann Thorac Surg. 2001;71:1949-58.

18. Taggart DP, Altman DG, Gray AM, Lees B, Gerry S, Benedetto U, et al; ART Investigators. Randomized trial of bilateral versus single internal-thoracicartery grafts. $N$ Engl J Med. 2016;375:2540-9.

19. Society of Thoracic Surgeons. STS adult cardiac surgery database data specifications version 2.81. March 28, 2014. Available at: https://www.sts.org/sites/ default/files/documents/ACSD_DataSpecificationsV2_81.pdf. Accessed March 9, 2018.

20. Knapik P, Spyt TJ, Richardson JB, McLellan I. Bilateral and unilateral use of internal thoracic artery for myocardial revascularization. Comparison of extubation outcome and duration of hospital stay. Chest. 1996;109:1231-3.

21. Taggart DP, Altman DG, Gray AM, Lee B, Nugara F, Yu L, et al. Randomized trial to compare bilateral vs single internal mammary coronary artery bypass grafting: 1-year results of the arterial revascularisation trial (ART). Eur Heart J. 2010;31:2470-81.

22. Benedetto U, Amrani M, Raja SG, Harefield Cardiac Outcomes Research Group. Guidance for the use of bilateral internal thoracic arteries according to survival benefit across age groups. J Thorac Cardiovasc Surg. 2014;148:2706-11.

23. LaPar DJ, Crosby IK, Rich JB, Quader MA, Speir AM, Kern JA, et al; Investigators for the Virginia Cardiac Surgery Quality Initiative. Bilateral internal mammary artery use for coronary artery bypass grafting remains underutilized: a propensity-matched multi-institution analysis. Ann Thorac Surg. 2015;100:8-15.
24. Dalén M, Ivert T, Holzmann MJ, Sartipy U. Bilateral versus single internal mammary coronary artery bypass grafting in Sweden from 1997-2008. PLoS One. 2014;9:e86929.

25. Mastrobuoni S, Gawad N, Price J, Chan V, Ruel M, Mesana TJ, et al. Use of bilateral internal thoracic artery during coronary artery bypass surgery in Canada: the bilateral internal thoracic artery survey. J Thorac Cardiovasc Surg. 2012;144: 874-9.

26. Sajja LR, Beri P. Bilateral internal thoracic artery grafting in India-time to raise the bar. Indian Heart J. 2017;69:640-5.

27. Locker C, Schaff HV, Dearani JA, Joyce LD, Park SJ, Burkhart HM, et al. Multiple arterial grafts improve late survival of patients undergoing coronary artery bypass graft surgery: analysis of 8622 patients with multivessel disease. Circulation. 2012:126:1023-30.

28. Grau JB, Ferrari G, Mak AWC, Shaw RE, Brizzio ME, Mindich BP, et al. Propensity matched analysis of bilateral internal mammary artery versus single left internal mammary artery grafting at 17-year follow-up: validation of a contemporary surgical experience. Eur J Cardiothorac Surg. 2012;41:770-6.

29. Luthra S. Degrees of belief and the burden of proof: the ART Trial. Ann Thorac Surg. 2017;104:1441-4.

30. Kurlansky PA, Traad EA, Dorman MJ, Galbut DL, Ebra G. Bilateral versus single internal mammary artery grafting in the elderly: long-term survival benefit. Ann Thorac Surg. 2015;100:1374-82.

31. Endo M, Tomizawa Y, Nishida H. Bilateral versus unilateral internal mammary revascularization in patients with diabetes. Circulation. 2003;108:1343-9.

32. Pevni D, Medalion B, Mohr R, Ben-Gal Y, Laub A, Nevo A, et al. Should bilateral internal thoracic artery grafting be used in patients with diabetes mellitus? Ann Thorac Surg. 2017;103:551-8.

33. Deo SV, Shah IK, Dunlay SM. Bilateral internal thoracic artery harvest and deep sternal wound infection in diabetic patients. Ann Thorac Surg. 2013;95:862-9.

34. Benedetto U, Altman DG, Gerry S, Gray A, Lees B, Pawlaczy R, et al. Pedicled and skeletonized single and bilateral internal thoracic artery grafts and the incidence of sternal wound complications: insights from the arterial revascularization trial. J Thorac Cardiovasc Surg. 2016;152:270-6.

35. Holmes DR Jr, Kip KE, Kelsey SF, Detre KM, Rosen AD. Cause of death analysis in the NHLBI PTCA Registry: results and considerations for evaluating longterm survival after coronary interventions. J Am Coll Cardiol. 1997;30:881-7.

Key Words: CABG, arterial grafts, outcomes, statistics, propensity matching, coronary artery bypass grafts

\section{Discussion}

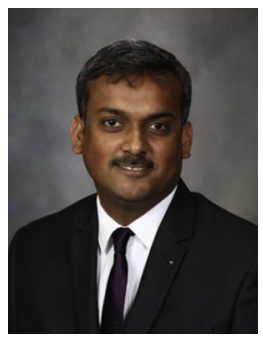

Dr Nishant Saran (Rochester, Minn). Last year, the 5-year results of ART were published, which showed essentially no difference in survival benefit at 5 years between the BITA and the single ITA groups. This brings back into focus the debate between BITA and LITA. For the last 1.5 decades, the evidence has shown that use of BITA is superior to the use of LITA alone, and despite this evidence, there has been a low worldwide use rate of BITA, with $4 \%$ in the United States and 12\% in Europe and Australia. So why has there been an inherent resistance, despite the evidence, among the surgeons to embrace BITA more liberally? This has been because of the perception of poor results of BITA in patients with perceived high-risk factors, such as advancing age, low EF, obesity, diabetes, and CLD. Of course, in the current era the surgeon is 
pressured to look into improved short-term outcomes and operating room turnover times; an extra half an hour for BITA tends to push the surgeon the other way. We looked into identifying the trends in BITA use in our practice to ascertain if there is a survival benefit and find if this survival benefit persisted in the high-risk groups. We retrospectively reviewed 9084 patients from January 2000 to 2015 who received CABG at our institution. We included patients who had 2 or more grafts and had BITA or LITA use alone. We excluded patients with single grafts, use of RITA alone, or concomitant cardiac surgery. We found 6468 patients with isolated multivessel CABG. Of these, 1037 patients were in the BITA group and 5431 patients were in the LITA group. To achieve a comparable matched group, we did the propensity score matching and found a matched pair set of 1011 patients. We did a survival analysis between these 2 groups and found the differential effect of BITA on the survival in the high-risk groups, where the high-risk groups were defined as EF less than $30 \%$, BMI more than 30 , age more than 70 years, and patients with CLD or stroke. What we found in our study was since 2012, there was a doubling in the rate of use of BITA from $12 \%$ in 2012 to $27 \%$ in 2015 . This was the result of our own analysis published in 2012, wherein we found that multiarterial grafts had a better survival benefit compared with LITA-vein. Excuse me for this busy slide, but I have used this to convey the message of the exhaustive list of variables we included to match the patient subsets.

When we look into the unmatched subset, we find that the BITA patients are younger and have lesser diabetes and lower BMI, and are less often female. Patients with LITA alone have 4 times the chance of being in congestive heart failure. Stroke and CLD were twice as common in the LITA alone group, whereas patients with BITA had better heart function. This unmatched set shows the clear treatment selection bias we have. BITA goes to the healthier patient set, and to remove this treatment selection bias, we wanted to achieve a propensity matching that would give us a standardized difference of 0.0 for all these variables. We found 1011 pairs of patients with this matching. To convey the effectiveness of the matching, here is the slide where we see the distribution of the propensity score between the matched sets. When we evaluated our results, of course the SVGs were more common in the LITA alone group, but the radial grafts were also more common in the LITA alone group. Perfusion time was lower in the BITA group, although the crossclamp time was higher in the BITA group. Of course, incision time was approximately 40 minutes more than in the LITA alone group. When we looked into the postoperative outcomes, the ICU length of stay was lower in the BITA group, but the sternal infection, both superficial and deep, was twice as common in the BITA group. The deep sternal infection, although the numbers were slightly higher in the BITA group, was not statistically significant. In terms of survival, with a $P$ value of .03, we found that the BITA cases tend to do better than the LITA-alone cases. The Kaplan-Meier curves clearly show the difference at 5 years too, with $93.8 \%$ of the BITA cases surviving. The curves really tend to diverge after the first 7 to 8 years with 10-year results of $19 \%$ risk reduction in death in BITA cases.

Having established a survival benefit, we looked into the high-risk factors, and you see from this slide, in patients aged more than 70 years, the HRs were still protective in the BITA group. The HR for patients aged more than 70 years was 0.75 , not much different from the HR with age less than 70 years. For women, the HR is not much different. For BMI more than 30, the HR was pretty much unchanged, the interaction being just 0.87. Lower $\mathrm{EF}$, the HR with BITA cases was actually better at 0.54 , but there was no significant interaction. For diabetes, the HRs were better. For stroke, the HRs were unchanged. For CLD, the HRs were better with BITA cases. In patients with nonelective surgery, the HRs were pretty much unchanged, thereby suggesting that the survival benefit of BITA persisted in all these high-risk groups that we looked into. Having established this, we then looked into the higher risk of sternal-site infections, and whether the higher risk persisted if we adjust for the risk factors, which included gender, diabetes, BMI more than 30 , CLD, and the year of surgery. In the earlier years, pedicled thoracic harvesting technique was more common than skeletonized, whereas the use of aspirin and statins was common in the latter era. We found that the risk of sternal site infections was 2 times higher with BITA, but we found no significant difference in deep sternal infections. This higher risk persisted with an OR of 2.39 despite adjusting for the high-risk factors.

This study has the limitations of being a retrospective single-center study and our inability to control for all the possible variables despite the best possible efforts to use an exhaustive list of measurable variables, but then there will always be variables that you cannot measure (eg, patient fitness).

There is an increasing use rate of BITA at our institution, and the favorable outcomes of BITA persist in perceived high-risk patients; therefore, there should be a more extensive use of BITA in patients with multivessel CAD.

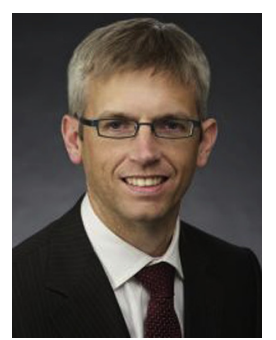

Dr Eric Lehr. More than 10 years ago, Bruce Lytle reported improved longterm survival at 9 years for BITA grafting even in patients with moderately or severely impaired left ventricular function. Likewise, in 2012, John Puskas showed superior 9-year survival after BITA grafting in both diabetic and nondiabetic patients. Despite these and many other data, 
less than $4 \%$ of CABG cases in the United States are afforded the benefits of BITA grafts. Across the 17 cardiac surgery programs reporting outcomes to the Cardiac Outcomes Assessment Program in the state of Washington, BITA use ranges from just $0 \%$ in most programs to $54 \%$ and only 1 program uses BITAs more than $10 \%$ of the time. It is important to consider that in the SYNTAX Trial, $28 \%$ of the patients in the randomized trial and $16 \%$ of patients in the registry received BITA grafts. Whether every patient benefits from BITA grafting remains undetermined. Despite the favorable observational trials, David Taggart, as you mentioned, published the 5-year data from the ART that failed to demonstrate a survival advantage for BITA at 5 years. I congratulate you and your co-authors for your persistence and successfully increasing BITA use in coronary vascularization at the Mayo Clinic. In your current study, you have shown improved survival for BITA grafting at 1,5 , and 10 years over patients receiving only a LITA graft with no difference in operative mortality. The cost of this $20 \%$ to $22 \%$ survival advantage in several high-risk patient subsets was a small increase in the incidence of sternal site infections but not deep sternal wound infections. I have several questions for you regarding your study. One, coronary disease complexity could influence surgeons against using BITA grafts and influences CABG outcomes, thereby introducing the possibility for bias. Did you consider including any assessment of the complexity of coronary disease, for example, the SYNTAX score and your propensity score?

Dr Saran. We did include patients with left main stenosis more than $50 \%$ as 1 of the variables. This study included patients with multivessel CAD as in 2-vessel and 3-vessel disease to account for the coronary anatomy that we were talking about. We did not include the SYNTAX scores. This is an STS database study.

Dr Lehr. It would be difficult to calculate the SYNTAX scores, but just looking at left main and simple 2- or 3-vessel diseases may not capture all of that bias. A number of different grafting strategies were used for the RITA. Could you detect if one approach provided a greater benefit to patients, and likewise, did any strategies fail to benefit patients?

Dr Saran. We did not specifically look into the grafting strategies. We did find that approximately $30 \%$ of our RITA grafts went to the right coronary, and despite the use of multiple grafting strategies and concern for use of RITA for right coronary grafting, we still found a survival benefit in favor of BITA.

Dr Lehr. Finally, should BITA grafting be considered a quality metric in coronary vascularization, despite the small increase in sternal site infections, even though sternal wound infections have been declared a never event and are tied to reimbursement.

Dr Saran. I agree with you, I think BITA should be the gold standard, and it should be the first thing that a surgeon, a coronary surgeon, should always think of when he/she meets a patient for CABG, and then look into things or concerns of why he/she cannot or may not be able to do it. But I guess the current trend of practice is different.

Dr Richard Shemin. Please identify yourself and where you're from.

Participant:___ (Lincoln, Neb). Did you examine the effects of multiple risk factors on outcomes with BITA use, such as patients who have obesity, diabetes, and CLD? How does the use of BITA affect that patient group?

Dr Saran. We did. So that's what the differential effect of all these high-risk groups looks into, and we found that essentially the survival benefit persisted in these high-risk groups. We also did a multivariate analysis that established the same thing.

Participant. But I'm asking in combination, if you have patients who have 3 risk factors versus no risk factors, 4 risk factors versus no risk factors?

Dr Saran. Right. So, in patients such as diabetic women with obesity, we did look into it specifically and found that survival benefit persisted, and there was no adverse differential effect on the survival benefit.

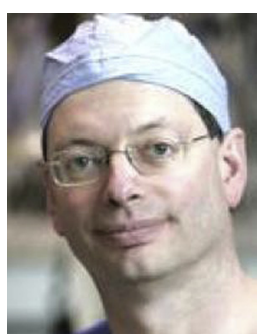

Dr Tony Furnary (Portland, Ore). I'm having trouble reconciling your main figure and your conclusion that there are significant improvements in survival with 2 survival curves that have 95\% composite intervals that overlap the entire way out. I'm wondering if you used the correct test to determine the difference in survival, because when I look at that or my statistical colleague Gary Grunkemeier looks at that, there's no difference in those curves. So, I'm not sure that the main premise is correct. Could you explain that?

Dr Saran. Sure. So, we did the log-rank test to establish the difference in our survival curves and, the $P$ value is definitely significant at .03 . I understand what you're saying that the curves look similar, but it's after 7 to 8 years they diverge. Statistical analysis proves it.

Dr Furnary. I'm not sure that's the correct test. I'm not sure you have shown a difference in survival in the longterm survival in these 2 groups. I think I would look at that closely. So, I don't want to argue with you about it, we'll let the statisticians determine that, but I don't think you've proven the main premise to me yet.

Dr Saran. In the survival analysis figure, the appearance of overlapping CIs between the 2 treatments does not imply the group difference is not statistically significant. It has been shown that, in general, lack of overlap between two 95\% CIs corresponds to an approximate $P$ value of less than .005 . Therefore, because our propensity analysis declared the survival curves different at $P=.03$, it is not too surprising to see those intervals overlap. Also in the Cox proportional hazard risk adjusting model, BITA was associated with $19 \%$ risk 
reduction with the HR being 0.80 and a $26 \%$ risk reduction after additional adjustment for all baseline covariates used in the propensity model with an HR of 0.74 .

Dr Furnary. Yes, we'll see what the reviewers say.

Dr Shemin. Yes?

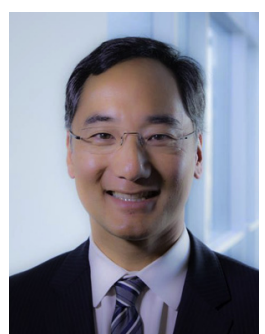

Dr Howard Song (Portland, Ore). Congratulations, this was a great study, spreading the gospel of arterial grafting, which as you pointed out, our country is lagging behind in. You went through the list of variables that you controlled for in your propensity matching. Did you control for surgeon?

Dr Saran. No we did not.

Dr Song. Does the rate of BITA use vary by surgeon in your institution?

Dr Saran. To be honest it may, but we looked into our institutional practice as a whole, and at the Mayo Clinic, normally the practice is a standardized one, but of course the surgeon preferences change and so will according to the patients.

Dr Song. Do you think it's possible that BITA use is a surrogate for a highly skilled subspecialist in coronary revascularization who you may expect to have improved outcomes over time?

Dr Saran. That may be one way of looking at it; however, even very skilled surgeons still have that inherent bias of not doing BITA. With the pressure of increased operating room turnover time and the short-sightedness of the short-term outcomes, I guess some of the surgeons do have that inherent reluctance in embracing BITA.

Dr Song. It is important as a message to the field that what these retrospective studies frequently show is that providers are skilled at picking the proper therapy based on both patient factors and their own skill level. I think a study like this doesn't necessarily show that every surgeon should be performing BITA use liberally; it shows that surgeons in your practice who do that do have excellent outcomes.

Dr Saran. I agree.

Dr Shemin. Very quickly, we have time for 1 more question.

Dr David Joyce (Milwaukee, Wis). That's an excellent point that was brought up, and I'd like to share with everyone kind of the nature of the practice at Mayo, and we have Chaim Locker here who is the second author on this article, and there's no question that we treat BITA use like anybody can do it. If you can take a LITA, you can do a BITA. It is like anything else, there's a 10,000-hour rule, and we are fortunate to have somebody who has exceptional skill in this operation, and I remember the first time I did a case with Dr Locker. He pulled the thoracic out of the right chest, wrapped it around the heart 3 times, and said, where do you want to put it. When you're working with that kind of expertise, you're going to be more likely to use a BITA. Just as he has a tremendous ability with this operation, he's a huge, passionate advocate for it, and I think you need somebody like that in your practice as well. I started to worry that if I didn't use a BITA, Chaim was going to send a bounty hunter after me or something if I didn't have a high use rate. I think it takes a lot of aggressiveness within your program, and there's no question that there's a skill level here.

Participant. Currently in your practice, are you doing skeletonized thoracic arteries on all thoracic take-downs?

Dr Joyce. Yes, my personal style, which may be different than everyone else in the group, if it's a LITA alone, I'll use it as a pedicle, but for BITA, skeletonization, and we're working on a follow-up study to show that we think we can bring that wound infection rate down by looking at the difference between skeletonized and pedicle, but we think there's going to be a difference there as well.

Participant. In large groups like yours, do you think it's worthwhile having a strategy to set a goal of how many bilateral thoracic arteries you should have in your practice given the literature and the fact that we appear to be laggards in achieving the goals that Europeans and other have been able to achieve?

Dr Joyce. Absolutely. That was really 1 of the goals of this study. We don't really know what the max...I mean just like with off-pump or anything else, the correct percentage that we should have is probably not $100 \%$, it's somewhere between where we are now and something much higher than that. What I hope we've shown here is that maybe it's certainly north of $15 \%$, and so setting that goal makes a lot of sense to me and then we take it from there. 